\title{
An Investigation of the Tender Nut Potential of Diverse Coconut (Cocos nucifera L.) Varieties/Forms in Sri Lanka
}

\author{
S.A.C.N. Perera ${ }^{1}$, G.K. Ekanayake ${ }^{2}$ and H.M.N.B. Herath ${ }^{3}$
}

\begin{abstract}
There is a rising demand in the world for coconut water as a healthy natural beverage. Different coconut varieties are used in different countries to be processed as a natural drink. The coconut form "King coconut" has long been used in Sri Lanka as the ideal coconut variety for this purpose. However, with the expansion in the local and export beverage coconut market, the supply does not meet with the demand at present. Therefore, this study was conducted to identify potential coconut varieties/forms mainly relating to the yield of beverage. The study was conducted in the main coconut triangle and Southern Sri Lanka. Eleven coconut forms, namely, King coconut and Bothal thembili in the variety Aurantiaca, Red, Yellow, Green and Brown dwarf and Murusi in the variety Nana, Bodiri, Dothalu, and Sri Lanka tall. These are included in the variety Typica along with Nipol, which is a natural hybrid being identified to be suitable as beverage coconuts. Out of them the yielding ability was high in King coconut, Red dwarf and Yellow dwarf while Bodiri, Nipol and Dothalu fared well. Many coconut forms suitable for beverage purpose were observed to be having seasonality in nut production. Ensuring adequate soil fertility and prevention of water deficit over prolonged periods were observed to help sustain yield and reduce seasonality in bunch emission. There were no large scale plantations for beverage coconuts in Sri Lanka, and the entire collection was from home gardens and very small scale holdings. It is recommended to establish medium scale holdings with coconut forms having high yield potential as identified in the current study, with proper management guidance to ensure a steady supply of beverage coconuts to the local as well as export market.
\end{abstract}

Keywords: Beverage, Coconut, Cocos nucifera, King coconut, Varieties

\footnotetext{
Coconut Research Institute, Lunuwila, Sri Lanka.

${ }^{1}$ chandrikaperera2003@yahoo.com

22gkekanayake@yahoo.com

${ }^{3}$ hmmbherath1@yahoo.com
} 


\section{Introduction}

Currently, there is a worldwide demand for coconut as a natural beverage. Coconut water became a popular natural beverage firstly in the coconut producing countries in Asia and in Brazil and later in western countries, where a huge demand has been created at present. There is a very high international demand for coconut water, especially in the United States of America, and spreading in the Europe and Middle Eastern Countries as well.

Coconut water has gained recognition as a healthy non-alcoholic natural beverage, suitable as a restorative energy and sports drink. Coconut water is rich in ions and minerals containing, Potassium (at high concentration) and Magnesium, Calcium, Phosphorous, Iron, Copper, Sulphur, Chlorides, Sodium as well as amino acids and vitamins $\mathrm{B}$ and $\mathrm{C}$. Coconut water is equally beneficial for everyone including children and the aged. It is of pleasant taste and has the added bonus of a low concentration of sugar in comparison to many other natural beverages.

Almost all of the main coconut growing countries are in Asia except Brazil. Indonesia, the Philippines, India, Brazil and Sri Lanka are the major coconut growing countries. Out of them the main economic product in Brazil is tender coconut water, while kernel and copra products have been economically more important in Asia. Despite this, there are expanded tender coconut industries in Asian countries such as India and Thailand. In these countries different varieties and hybrids are used for beverage purposes. In India, Chowghat Orange Dwarf has been found to be the best tender nut variety followed by Malayan Orange Dwarf and Philippine Ordinary (Dhamodaran et al., 1993). An aromatic and other dwarf varieties are popular in Thailand and other South East Asian countries. Although there may be several varieties suitable as tender coconuts there is competition for them to be used in other industries especially kernel based products such as oil and copra.

Sri Lanka is the $5^{\text {th }}$ largest coconut producer and has the highest per capita consumption of coconut in the world. The estimated per capita consumption of coconut in Sri Lanka is around 110 nuts/year (Anon, 2009) and $80 \%$ of the production is consumed domestically. Much of the production is used in kernel-derived products: oil; copra; and desiccated coconut; in addition to the use of mature green nuts in daily cuisine. However, consumption of both tender and mature coconut water as a beverage has been a tradition in Sri Lanka over a long period of time and there are certain varieties preferred for this purpose.

The semi tall coconut variety King Coconut (locally known as Thembili or Rath thembili) has long been known in Sri Lanka as the ideal variety for tender coconut beverage purpose (Liyanage, 1958; Bandaranayake and Fernando, 1999). King coconut is intermediate in form between tall and dwarf. It is semi tall, has a medium height growth rate, produces a root bole and is predominantly self pollinating. It bears profusely fruit having an orange epicarp. King coconut production in Sri Lanka is almost exclusively for tender coconut water. However, there are several other varieties which are less commonly used for beverage purposes and yet with a higher potential productivity as beverage coconuts. Therefore this study was conducted with the objective of identifying varieties having a potential for beverage production and studying some of their specific characteristics which make them suitable for tender nut purposes.

\section{Materials and methods}

A field survey was conducted in Puttalum, Chillaw and Gampaha in the main coconut triangle in the North Western province and Galle, Unawatuna area in the Southern Sri Lanka. The coconut varieties which were used for beverage purposes were identified.

Approximately 30 palms (except for Dothalu and Nipol in which the sample sizes were smaller) of each of the identified varieties were used for recording the variables: number of bunches; number of nuts in each bunch; nut water volume at 7-8 month maturity stage; seasonality in bunch emission; and nut setting. Observations were made over a period of one year and data were analysed by deriving means 
Table 01. Coconut varieties used as beverage coconuts at the tender nut stage

\begin{tabular}{|c|c|c|}
\hline Common name & $\begin{array}{l}\text { Variety/form (in Sri } \\
\text { Lankan classification) }\end{array}$ & Distribution and occurrence of palms \\
\hline Thembili & Aurantiaca/King coconut & Throughout the coconut growing areas. \\
\hline Bothal Thembili & Aurantiaca/Bothal thembili & Only in the Southern Province of Sri Lanka \\
\hline Red Dwarf & Nana/Red Dwarf & Throughout the country. More common in the Southern Province. \\
\hline Green Dwarf & Nana/Green Dwarf & Throughout the country. More common in the Southern Province. \\
\hline Brown Dwarf & Nana/Brown Dwarf & Throughout the country. More common in the Southern Province. \\
\hline Yellow Dwarf & Nana/Yellow Dwarf & Throughout the country. More common in the Southern Province. \\
\hline Murusi & Nana/Green Dwarf 'Murusi' & Only in the Southern Province of Sri Lanka \\
\hline Bodiri & Typica/Bodiri & Throughout the country. More common in the Southern Province. \\
\hline Dothalu & Typica/Dothalu & Only in the Southern Province of Sri Lanka \\
\hline Nipol* & A natural hybrid & Throughout the country \\
\hline Sri Lanka Tall & Typica/Typica & Throughout the country \\
\hline
\end{tabular}

* Nipol is a natural hybrid between King coconut and Sri Lanka tall

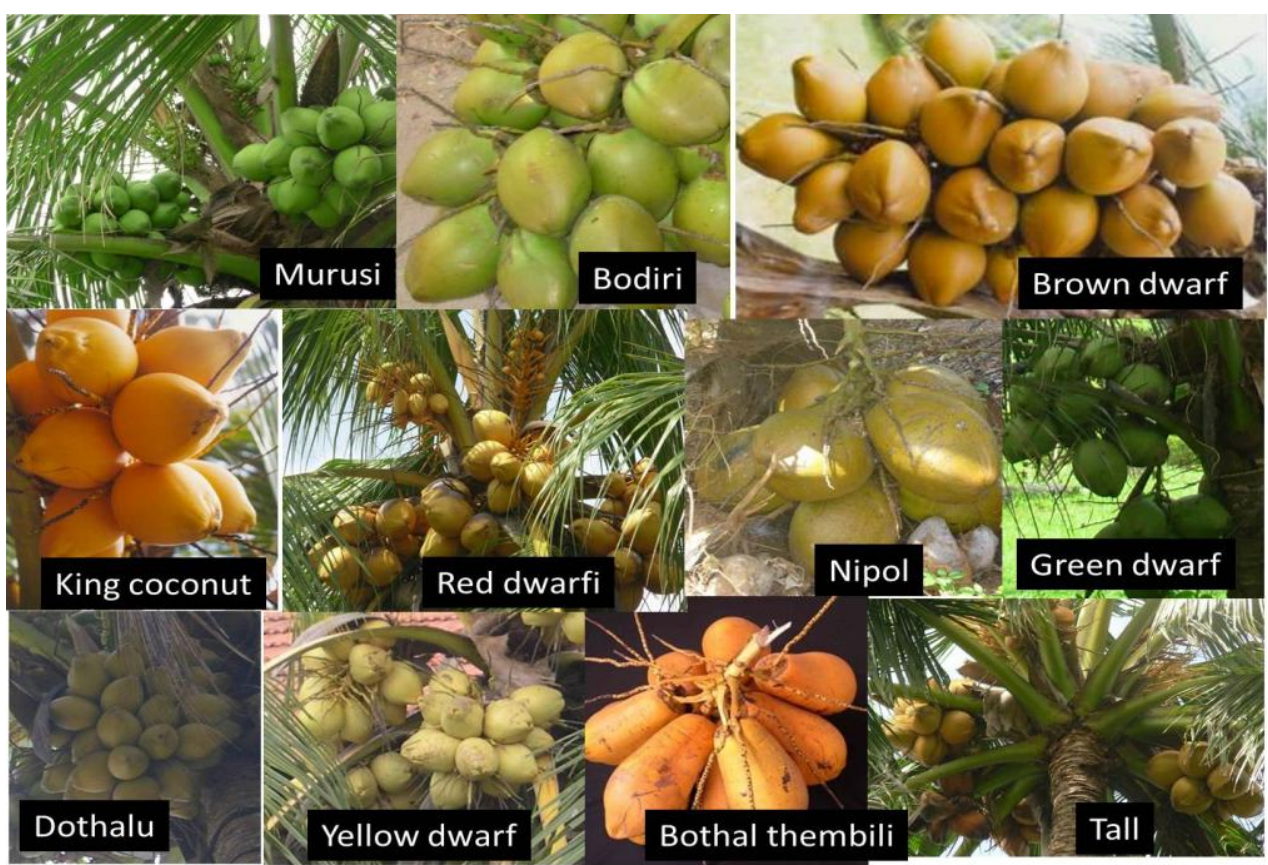

Figure 01. Coconut forms used as tender nut beverage in Sri Lanka 
and performing an analysis of variance and mean separation in statistical software SAS v8.

\section{Results and discussion}

\section{Varieties used for beverage purpose in Sri Lanka}

The results revealed the presence of several varieties/forms which are used for beverage at the tender nut stage (Figure 01). Out of them, King Coconut was identified to be the dominant variety for beverage purpose in Sri Lanka. The other varieties were used in more limited quantities at the tender nut stage (Table 01).

Thembili (King coconut) exceeded $75 \%$ of the tender nut market in Sri Lanka. Also the main purpose of growing Thembili was to be used as beverage at the tender nut stage; being 7 8 months of developmental from flowering. The coconut form Red Dwarf was also highly valued as beverage coconuts. The general public could not distinguish the fruit of Thembili and Red dwarf due to the close morphological similarity of the fruit forms. The pericarp colour of both was orange while the only visual difference was the unique button-like protrusion at the tip of Thembili fruit. The remaining dwarf forms; green, yellow and brown, were used in limited scale as beverage being less common, especially in the main coconut triangle of the country. The main commercially grown cultivar, Sri Lanka tall was occasionally used for beverage purposes all over the country. The other listed two tall forms, Dothalu and Bodiri were also used because their smaller nut size made them less desirable for processing into kernel products. Both were rare and found only in the Southern Province of Sri Lanka. Murusi has the phenotype of the Green Dwarf very common in the home gardens of Southern province. It was a very popular beverage form in the south of Sri Lanka. Bothal thembili was also found only in the south being a form related to the variety Aurantiaca, but with a different nut shape (Figure 01). Bothal thembili was also a source of beverage. Among the various forms used for beverage in Sri Lanka, are several different phenotypes which are not found in the main coconut triangle, but only in the south. The wide occurrence together of the Tall along with King variety in home gardens has simultaneously given rise to Nipol, a natural hybrid. While the King coconut is naturally self-pollinating there is some outcrossing. Therefore, when the farmers collect seednuts of the King coconut there would be a low percentage of Nipol hybrid seedlings due to pollen shed by the surrounding Tall palms.

Evaluation of the potential of different varieties/forms for beverage purpose

The yield variables related to quantity of nut water measured at the 7-8 month developmental stage of the nuts are presented in Table 02.

Number of bunches emitted during a given period, number of nuts produced in each bunch and the volume of nut water at the appropriate stage are the main yield components. These variables were significantly different among the studied coconut forms (Table 02). Bodiri recorded the highest values for both bunch emission and the nut production. However, the nuts of Bodiri were smaller resulting in a lesser amount of water per nut. It was observed that when the number of nuts per bunch was higher the size of the nuts became smaller and viceversa in prolific bearers: Green Dwarf; Brown Dwarf; Murusi; Bodiri; and Dothalu, resulting in lesser volume of water per nut. This factor was not prominent in the other phenotypes. Clearly the above values need be considered in combination rather than in isolation to determine the yield potential of different varieties and forms for beverage purpose. The total volume of nut water calculated in this manner in each coconut form/variety is presented in Figure 02.

As presented in Figure 02, Red Dwarf, King Coconut and Yellow Dwarf were the highest yielders in that order, each recording volumes exceeding 50 litres per palm in the annum. Bodiri, Nipol, Sri Lanka Tall and Dothalu were also higher yielders while the rest of the dwarf varieties along with Bothal thembili recording volumes in the range of 30-40 litres of nut water per palm in the annum. 
Cord 2015, 31 (1)

Table 02. Beverage related yield variables of different coconut varieties/forms

\begin{tabular}{|l|c|c|c|c|}
\hline Common name & $\begin{array}{c}\text { Mean number of } \\
\text { bunches in the } \\
\text { year }\end{array}$ & $\begin{array}{c}\text { Total nut } \\
\text { production in the } \\
\text { year }\end{array}$ & $\begin{array}{c}\text { No. of } \\
\text { nuts/bunch }\end{array}$ & $\begin{array}{c}\text { Volume of } \\
\text { water/nut }(\mathrm{mL})\end{array}$ \\
\hline Thembili & $15.6^{\mathrm{b}}$ & $156^{\mathrm{c}}$ & 10.0 & $352^{\mathrm{bc}}$ \\
Bothal thembili & $13.6^{\mathrm{cd}}$ & $108.8^{\mathrm{e}}$ & 8.0 & $316^{\mathrm{d}}$ \\
Red Dwarf & $15.5^{\mathrm{b}}$ & $164.3^{\mathrm{c}}$ & 10.6 & $346^{\mathrm{c}}$ \\
Green Dwarf & $14.6^{\mathrm{bc}}$ & $150.2^{\mathrm{cd}}$ & 10.3 & $231^{\mathrm{ef}}$ \\
Brown Dwarf & $13.2^{\mathrm{d}}$ & $137.3^{\mathrm{d}}$ & 10.4 & $236^{\mathrm{ef}}$ \\
Yellow Dwarf & $14.1^{\mathrm{c}}$ & $138.2^{\mathrm{d}}$ & 9.8 & $378^{\mathrm{b}}$ \\
Murusi & $14.2^{\mathrm{c}}$ & $149.1^{\mathrm{cd}}$ & 10.5 & $252^{\mathrm{e}}$ \\
Bodiri & $16.5^{\mathrm{a}}$ & $221.1^{\mathrm{a}}$ & 13.4 & $224^{\mathrm{f}}$ \\
Dothalu & $14.2^{\mathrm{c}}$ & $184.6^{\mathrm{b}}$ & 13.0 & $218^{\mathrm{f}}$ \\
Nipol & $13.5^{\mathrm{d}}$ & $140.4^{\mathrm{d}}$ & 10.4 & $336^{\mathrm{c}}$ \\
Sri Lanka Tall & $13.5^{\mathrm{d}}$ & $91.8^{\mathrm{e}}$ & 6.8 & $448^{\mathrm{a}}$ \\
\hline
\end{tabular}

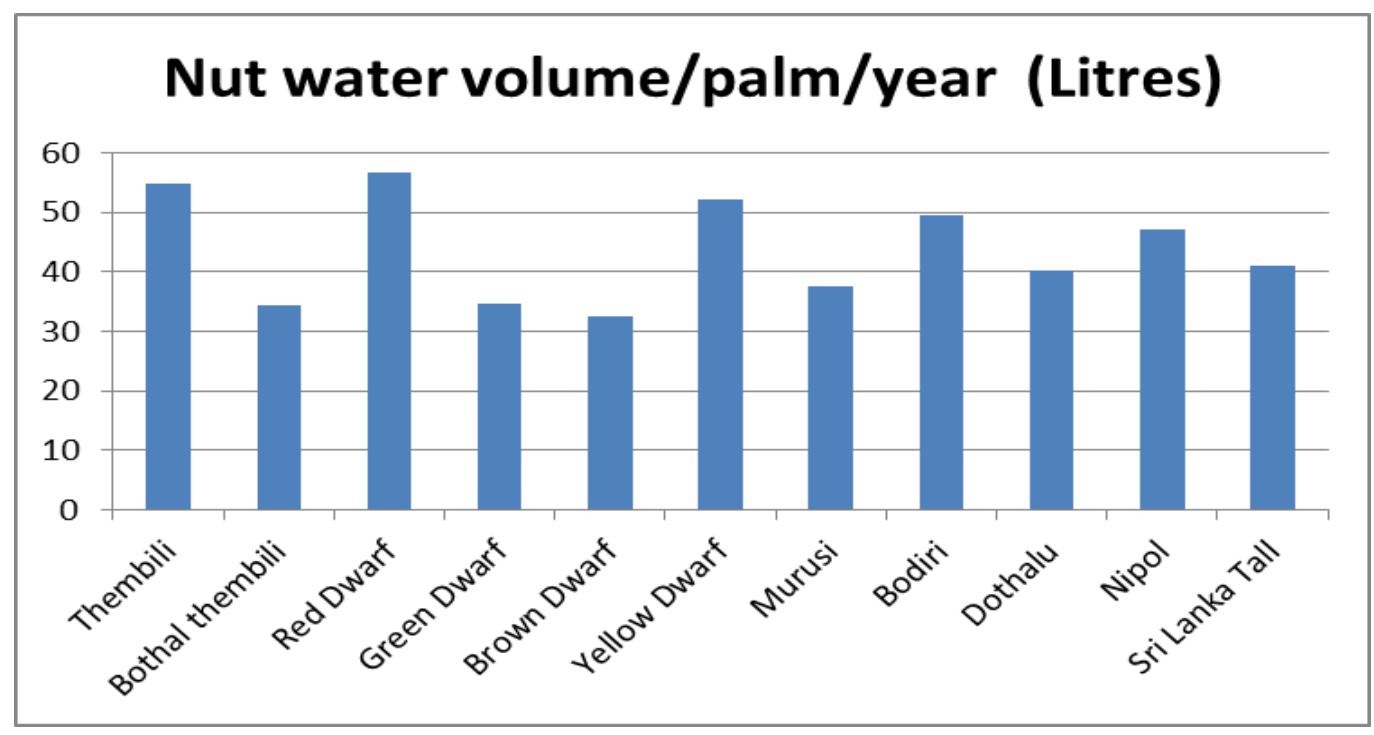

Figure 02. Annual volume of nut water in diverse coconut varieties/forms 


\section{Seasonality in nut production}

Seasonality in bunch emission was observed to varying degrees in all the coconut forms studied. In general bunch emission was low in the months of December to February in all the forms including the widely grown commercial Sri Lanka Tall, which is known to be hardy and more tolerant to variation in environmental conditions. During this period the number of bunches, number of nuts per bunch, as well as the nut size, were observed to be less. In addition, the dwarfs (except Yellow Dwarf), Bodiri and Dothalu, showed clear lean periods in both bunch emission and nut production. This seasonality was less common in King Coconut, Red Dwarf and Nipol when they were under good management and when the palms were not subjected to prolonged periods of water deficit.

\section{Potential varieties/forms as tender nut beverage coconuts}

In Sri Lanka the predominantly grown tender nut beverage coconut variety is King Coconut or Thembili, in local dialect. The present study provided evidence for the equal potential of Red Dwarf and Yellow dwarf with respect to yielding ability and hence need to be promoted in the development of tender nut beverage industry within Sri Lanka as well as to provide for the export market.

In the current study Nipol is the only hybrid that was tested. Nipol is not a recommended coconut hybrid in Sri Lanka. However, this natural hybrid proved to have a high potential for beverage production. Similarly, the recommended hybrids between tall and dwarf coconuts have been known to have a high potential or beverage (Dhamodaran et al., 1993) However, in Sri Lanka, there is a very high competition for the nuts of these recommended hybrids for different uses mainly for kernel products, limiting their availability for beverage. This situation is more so for the most expansively grown commercial coconut cultivar, Sri Lanka Tall, which is almost entirely harvested at the mature stage and used in kernel based products. Therefore, in Sri Lanka it is advisable to concentrate on the coconut forms which have been identified as having a high potential as beverage coconuts. This will avoid competition with processors seeking supplies of mature. Collection of coconut water from the mature nut at the processing plant of kernel products is also done. Alternative techniques are needed in processing this mature nut water for beverage purpose instead of discarding it. In this method a smaller amount of water will be obtained per nut but there will be the twin advantage of deriving kernel products and saving the mature nut water for a separate beverage market.

The composition of nut water is an important quality issue in beverage coconuts that has not been considered in the current study. However, earlier studies have reported that the composition of nut water depended on the stage of maturity of the nut (Nathanael, 1970). The desirable palatability of King coconut and other beverage forms mainly depends on the sugars and mineral components present. The maximum concentration of sugar and optimum levels of minerals and vitamins are found at the 7-8 months stage from the pollination (Gunawardena, 1973; Ediriweera, 1996). The sugar component comprises a larger portion of reducing sugars compared to non-reducing sugars (Mohandas, 1982). With the ripening of the nuts major changes in composition of sugars takes place. There may be genetic differences in these factors in the potential beverage varieties identified in this study and future research efforts on the biochemical aspects could help in developing the quality of beverage coconuts.

Beverage coconuts are not grown in plantation scale in Sri Lanka but only in home gardens or as small blocks adjacent to larger plantations. However, with the huge increase in local and international beverage there is an urgent need for establishing larger scale coconut holdings for beverage coconuts. With the information derived in the current study suitable varieties for this purpose can be selected to provide a generically diverse population of nut water producing palms.

The coconut forms King coconut, Red Dwarf and Yellow dwarf are the best suited forms throughout the country. In addition, Bodiri 
and Nipol will also be very high yielders. Using Sri Lanka tall and recommended coconut hybrids will not be practical due to the demand for kernel products. There is a need to rationalise management of the tender nut beverage coconut holdings. Regional diversity could avoid localised periods of water deficit and overcome seasonality and to stabilise the supply of nuts. With adequate soil fertility and soil moisture supply, all the dwarf forms can be promoted as suitable for tender nut beverage purposes in Sri Lanka.

\section{Acknowledgments}

This research was conducted with the financial assistance from the Coconut CESS Fund in Sri Lanka. Authors are grateful to Dr. L. Perera, Head of the Genetics and Plant Breeding Division and Dr. J.M.D.T. Everard, former Deputy Director of the Coconut Research Institute of Sri Lanka, for their assistance and comments.

\section{References}

Anonymous 2009. Annual Report of the Central Bank of Sri Lanka.

Bandaranayake, C.K. and Fernando, W.M.U. 1999. Genetic improvement of King coconut, Cocos nucifera var. aurantiaca in Sri Lanka. Plant Genetic Resources Newsletter No. 118:30-33.

Dhamodaran, S., Ratnambal, M.J., Chempakam, B., Pillai, R.V. and Viraktamath, B.C. 1993. Evaluation of tender nut water in coconut cultivars. In: Proceedings of the International Symposium on Advances in Coconut Research and Development ISOCRAD II (Eds: M.K. Nair, H.H. Kan, $\mathrm{P}$.

Ediriweera, N.D. 1996. King coconut. CORD, XII No.2:43-47.

Gopalasundaram and E.V. Bhaskara Rao). Oxford \& IBH Publishing Co. Pvt. Ltd., New Delhi. pp. 123-128.
Gunawardena, M. 1973. A study of the free amino acids in the liquid endosperm of coconut. Ceylon Coconut Quarterly 24:102-106.

Liyanage, D.V. 1958. Varieties and forms of the coconut varieties grown in Ceylon. Ceylon Coconut Quarterly 11:43-51.

Mohandas, S. 1982. Report of the coconut processing division. Ceylon Coconut Quarterly 33:48-56

Nathanael, W.R.N. 1970. Non-conventional uses and processing techniques for coconut products. Ceylon Coconut Quarterly 21:99-106. 